\title{
Review of Recent Guidelines and Consensus Statements on Hereditary Angioedema Therapy with Focus on Self-Administration
}

\author{
M. Cicardi ${ }^{a}$ T.J. Craig ${ }^{b} \quad$ I. Martinez-Saguer ${ }^{c} \quad$ J. Hébert ${ }^{d}$ H.J. Longhurst ${ }^{\mathrm{C}}$ \\ a University of Milan and Luigi Sacco Hospital, Milan, Italy; ${ }^{b}$ College of Medicine, Penn State University, \\ Hershey Medical Center, Hershey, Pa., USA; ' Johann Wolfgang Goethe-University Hospital, Frankfurt, Germany; \\ ${ }^{\mathrm{d}}$ Laval University, Quebec, Que., Canada; ${ }^{\mathrm{e}}$ Barts Health NHS Trust, London, UK
}

\section{Key Words}

Hereditary angioedema · Self-administration · Consensus ·

Guidelines

\begin{abstract}
Consensus meetings and the resulting recommendations shape treatment choices in rare diseases such as hereditary angioedema (HAE) because they combine the experience of prescribing physicians and the patients who are receiving therapy. Self-administration of HAE therapy was recognised as a potential treatment option in the first consensus publication in 2003. Recent studies have confirmed that self-administration of therapy resolves attacks quickly, safely and minimises burden of disease; however, the discovery of inconsistent treatment approaches is a concern and warrants investigation into the barriers that prevent adherence with current recommendations.

Copyright $\odot 2013$ S. Karger AG, Basel
\end{abstract}

\section{Introduction}

Recommended approaches to the treatment of hereditary angioedema (HAE) have been documented since 2003 when a consensus was reached on its diagnosis, ther-

\section{KARGER}

E-Mail karger@karger.com

www.karger.com/iaa apy and management $[1,2]$. Consensus meetings and the resulting recommendations shape treatment approaches in rare diseases where there is a paucity of clinical trials because they combine the valuable experience of prescribing physicians and the patients who are receiving therapy. Over recent years the results of phase III trials and observational studies have enhanced our understanding of HAE and consensus documents have been updated to reflect these developments. Most recently a global guideline, sponsored by the World Allergy Organization (WAO), was published in response to the consensus statements with the intent to standardise care for patients with HAE throughout the world [3]. Self-administration of HAE therapy was recognised as a potential treatment option in the first consensus document $[1,2]$ and has since been shown to be efficacious, safe and convenient [4]. Self-administration also offers the prospect of patients being able to manage symptoms while maintaining personal safety with minimal disruption in day-to-day life. The terminology used within the referenced material refers to both home therapy and self-administration. It is the understanding that home therapy/self-administration refers to treatment given in a non-healthcare setting by the patient, or a trained partner, outside of a healthcare facility. Here we review the development of consensus documents over time, focusing on self-administration of HAE treatment. 


\section{Ten Years of Developing Consensus Statements on HAE Therapy}

In 2003, a meeting of representatives from European and North American centres was held in Canada, with the aim of developing a consensus algorithm. In this meeting it was recommended that home-care $\mathrm{C} 1$ esterase inhibitor (C1-INH) therapy be offered to patients with HAE and that these patients should be allowed to keep a supply of C1-INH replacement for personal use at home to be either self-administered or infused by a caregiver [2].

In 2005, a new consensus document was published [5] which supported the previous recommendation that all C1-INH-deficient patients should be offered the opportunity for home possession of C1-INH. Self-possession was shown to reduce the time patients spend awaiting infusion [6]. It was noted that patients should be allowed to keep sufficient therapeutic dose of $\mathrm{C} 1-\mathrm{INH}$ to treat a laryngeal attack, as $50-75 \%$ have a life-threatening attack at some time $[7,8]$. It was advised that access to C1-INH for acute attacks should be optimised by home therapy training and that the management of patients who selfadminister C1-INH concentrate should be standardised. Recommendations were made and are presented in table 1 [5].

In the 2005 guidelines, recommendations were made on the topics that home therapy training programmes should cover (table 2) [5]. In order for self-administration to be effective, a care management plan and good local transport links to an emergency department were deemed essential. It was also recommended that family physicians of self-administering patients be informed of their treatment choice [5].

In cases where the patient did not wish to, or was unable to self-administer C1-INH therapy, patients could keep a supply of concentrate for their use under the supervision of a health worker. This self-possession would reduce the time patients spend waiting for infusions. Consensus was that such a programme should be accompanied by appropriate information that should be carried by the patient for presentation at the emergency department in case of an attack and should include strategies for resupply of concentrate. It was also acknowledged that home possession may have benefits for children in the time to treatment from onset of attack [5].

In 2007, a review of studies detailing the use of C1-INH concentrate and home therapy in patients with HAE was published [9]. Patients who self-administered C1-INH (or had treatment infused by a family member), either on-
Table 1. Recommendations for home therapy, 2005 ${ }^{\mathrm{a}}$ [5]

Criteria for entry on to the home treatment programme

- Proven C1-INH deficiency.

- The patient's use of and compliance with prophylactic therapy should be optimal.

- In order to maintain required infusion skills, the patient should normally require infusion of $\mathrm{C} 1-\mathrm{INH}$ at least every 3 months.

- The patient must be motivated to comply with the home therapy programme and all its implications and be willing to be responsible for giving their home therapy. Written consent confirming this must be obtained before the programme is commenced.

- The patient must be counselled regarding the risk of transmissible infections from a blood product. The patient should demonstrate an understanding of this and provide written informed consent to receive therapy.

- The patient must have a partner willing to attend the home therapy programme who will be present when therapy is required.

- Written confirmation of support for home therapy must be agreed with the patient's general practitioner, including emergency support or an agreed pathway of emergency care.

- The patient must have access to a telephone when administering therapy.

- The patient must have good venous access.

- The patient must agree to call for an ambulance if self-cannulation is unsuccessful when concentrate is required.

- In most circumstances, home therapy is not employed in children.

a These guidelines have developed since 2005 and have progressed to now offer self-administration to all willing patients [25, 26, 40]. C1-INH = C1 esterase inhibitor.

demand at the onset of an attack or as regular prophylaxis, experienced improved quality of life and reduced severity, duration and frequency of attacks [10-15]. An excellent safety profile was also observed. At that time, children with HAE were still not usually considered for home therapy in the UK. One of the studies in this review used on-demand C1-INH therapy as first-line therapy for children, with regular prophylaxis for those who suffered frequent attacks; severe attacks were prevented and hospital time and absence from school were reduced [15]. The review concluded that the option of home therapy should potentially be made available to all HAE patients, adults and children, including those who suffer infrequent attacks [9].

The 2007 consensus document extended the idea of self-infusion and recommended that, for early treatment 
Table 2. The home therapy training programme, 2005 [5]

The home therapy training programme should include the following key topics:

- Appropriate use of concentrate.

- Hand washing and aseptic technique.

- Supply and storage of concentrate and equipment.

- Preparation of equipment for administration of concentrate.

- Product checking procedure, i.e. dosage, expiry date.

- Demonstration of correct technique for reconstitution of solution.

- Cannulation with butterfly.

- Blood sampling pre-injection/infusion.

- Administration of injection/management of infusion.

- Management of adverse reactions.

- Automatically injectable adrenaline/epinephrine training (for treatment of anaphylaxis of infusion).

- Disposal of equipment.

- Documentation, e.g. accurate recording of batch number.

- Documentary evidence of the individual's training and competence.

- $\quad$ Receiving and monitoring infusion logs and other relevant documentation for any indication of difficulties.

- Investigating any adverse reactions/events and taking appropriate action.

- Keeping the specialist nurse/consultant immunologist informed of any relevant issues regarding care and treatment.

- Compliance with clinic visits.

- Performing an annual review of the individual's competence to administer injection/infusion.

- Liaising with the individual, his/her general practitioner, consultant immunologist and other relevant care providers.

of acute HAE attacks (and to facilitate prophylaxis where necessary), home C1-INH replacement self-infusion programmes should be offered to patients. These programmes are similar to the haemophilia self-infusion protocols which have been in use for over three decades [16]. The consensus meeting recommended that home self-infusion protocols should be available on patient websites and proposed the establishment of Comprehensive Care Clinics for the diagnosis, therapy and management of HAE, including the development of home infusion and home-care programmes. Comprehensive Care Clinics should be encouraged to register HAE patients in national and international database registries to facilitate research into the diagnosis and management of this disorder [17].

Although C1-INH (namely Berinert) has been approved in Germany for the treatment of acute HAE attacks since 1979 [18], C1-INH was only available on an individual 'compassionate use' basis in other parts of Eu- rope and only became available in the USA in the latter part of the last decade: Berinert was approved for the treatment of acute HAE attacks in 23 European countries in 2008 [19] and in the USA in 2009 [20]; Cinryze was approved by the Food and Drug Administration (FDA) for routine prophylaxis in 2008 [21] and for self-administration for prophylaxis in 2009 [22]. Around this time, two new products were licensed for the treatment of acute HAE attacks: ecallantide (Kalbitor, a kallikrein inhibitor) was licensed in the USA [23] and icatibant (Firazyr, a bradykinin $\beta_{2}$-receptor) was licensed in Europe [24].

In 2009, the HAE international home therapy consensus document was formulated [25]. Initially, most selfadministered treatment was limited to pasteurisednanofiltered C1-INH replacement. It was agreed that every patient with HAE should be considered for selfadministration training, once the diagnosis of C1-INH deficiency was confirmed. Extremes of age were no longer seen as a limiting factor in self-administration, although children needed a responsible adult willing to undertake training. It was strongly recommended that patients train with a 'home therapy partner' who would be able to provide support, advice and, where applicable, be trained to administer therapy. In the absence of a 'home therapy partner', it was recommended that extra care be taken with arrangements for medical back-up. Home therapy was recommended in pregnant and lactating women. It was stated that attacks at all sites could be selftreated; however, in the case of laryngeal oedema, patients should be urgently transferred to hospital after home therapy. Self-administration was found to be associated with a low incidence of 'cannulation failure' and could preserve veins more effectively than hospital-based care [25].

The consensus view was that the self-infusion training programme should be conducted over several sessions to ensure that the patient and treatment partner have sufficient practice to be familiar and confident with technical and medical aspects of self-administration. Prior to starting home therapy, the patient should have received the proposed home therapy at least once and have self-administered the therapy under medical supervision. The patient's and treatment partner's knowledge should be assessed upon completion of training and refresher training planned at least every 12 months [25]. Furthermore, it was noted that there was a need to optimise prophylaxis but home therapy need not be delayed since training can take place simultaneously with other treatments, and in most patients, attacks occur despite prophylaxis [25]. 
The 2010 international consensus algorithm for the diagnosis, therapy and management of HAE [26] agreed with the 2007 consensus document that home pasteurised-nanofiltered $\mathrm{C} 1-\mathrm{INH}$ self-infusion programmes should be offered to patients and be similar to haemophilia self-infusion programmes. It was also recommended that HAE patients be linked to a Comprehensive Care Clinic which must provide accountability for home- and hospital-based use of potentially toxic treatments, track patient outcomes and develop and meet Standards of Care for HAE. Comprehensive Care Clinic programmes should combine clinical care, education and research, and provide hospital-based patients with education of and accessibility to home therapy programmes.

Shortly after the release of these consensus documents, several phase III trials and other studies were reported [27-32] and the recommendations were updated to state that HAE patients should carry two doses of any of the HAE therapies. With the availability of newer treatments, the two doses could be plasma-derived C1-INH, recombinant human C1-INH, icatibant or ecallantide [33].

In 2011, Cinryze was granted European marketing authorisation for self-administration for routine prevention and treatment of acute HAE attacks in adults and adolescents [34]; also in 2011, Firazyr was approved by the FDA [35] and in Europe [36], and Berinert was approved in Europe [37] for self-administration of treatment for acute attacks. In 2012, Berinert was approved for self-administration for acute attacks in the USA [38]. Recently, Berinert was approved for short-term prophylaxis in Europe [39].

In 2012, evidence-based recommendations for the management of HAE were published by the Hereditary Angioedema International Working Group (HAWK) [40]. This consensus stated that all patients with HAE should have access to at least one therapy out of plasmaderived C1-INH, recombinant C1-INH, icatibant and ecallantide. Additionally, wherever possible, and permitted by specific prescribing guidelines, patients should have the on-demand medicine to treat acute attacks at home and should be trained to self-administer these agents. This recommendation was based on observations that greater efficacy of early on-demand treatment was reported compared with hospital therapy $[14,41]$. This consensus document concluded that further investigation is needed to determine whether implementation of aggressive early home on-demand treatment would reduce the need for prophylactic treatment in patients whose attacks are insufficiently controlled by standard on-demand treatment, and that a more proactive, pa- tient-centric approach towards HAE treatment needs to be implemented [40].

Finally, the WAO global guideline for HAE also endorsed self-care and home care of HAE by both consensus and evidence-based medicine [3]. The guideline was approved by the affiliated Allergy Immunology Associations worldwide. It emphasised that all therapies should be available to all patients with HAE worldwide and that home- and self-administration are preferred since they reduce morbidity, absenteeism, cost, disease burden and potential mortality, and improve quality of life.

\section{Consensus on Home Therapy in Children and Adolescents}

A consensus on therapeutic strategies in children and adolescents with HAE has recently been published. It concludes that home therapy with pasteurised-nanofiltered C1-INH is possible for trained and educated patients (or their parents or guardians) and that a home therapy regimen is reasonable when long-term prophylaxis is necessary; however, the frequency of attacks appropriate for this therapeutic option needs to be defined [42].

\section{Current HAE Treatment Options}

Currently there are two HAE treatment strategies licensed for self-administration: pasteurised-nanofiltered C1-INH and icatibant [4]. Several studies of self-administered HAE therapy have been published (table 3) and they confirm that self-administration of HAE therapy resolves attacks quickly and safely, and gives patients greater confidence in managing their condition. General consensus is such that self-administration should be offered to patients whenever possible.

\section{Compliance with Current Treatment Recommendations}

Consensus documents have been in circulation for almost a decade; however, a web-based survey in the USA conducted between October 2009 and February 2010 (at a similar time to the FDA approval of pasteurised-nanofiltered C1-INH), found that although more than $90 \%$ of the 172 responding physicians recommended treating acute HAE attacks, only half of them had used C1-INH to do so and very few had patients who self-treated (8.1\%) 
Table 3. Recent studies detailing home therapy in patients with HAE

\begin{tabular}{|c|c|c|c|}
\hline Author & Year & Therapy & Outcome \\
\hline Kreuz et al. [41] & 2009 & $\begin{array}{l}\text { Regular doses of pasteurised- } \\
\text { nanofiltered C1-INH }\end{array}$ & $\begin{array}{l}\text { Completely abolished incidence of laryngeal oedema and } \\
\text { reduced incidence of acute attacks. }\end{array}$ \\
\hline $\begin{array}{l}\text { Tourangeau } \\
\text { et al. [43] }\end{array}$ & 2012 & $\begin{array}{l}\text { On-demand C1-INH in clinic or } \\
\text { home setting }\end{array}$ & $\begin{array}{l}\text { Significant decreases in attack duration, pain medication use } \\
\text { and graded attack severity in home setting vs. clinic. }\end{array}$ \\
\hline Bygum et al. [45] & 2009 & Self-administered C1-INH & $\begin{array}{l}\text { Self-administration of C1-INH improved quality of life on } \\
\text { both physical and psychological parameters. }\end{array}$ \\
\hline Farkas et al. [46] & 2012 & $\begin{array}{l}\text { Icatibant administered by healthcare } \\
\text { providers for home treatment of } \\
\text { attacks }^{\text {a }}\end{array}$ & $\begin{array}{l}\text { All attacks resolved and safety was consistent with known } \\
\text { local tolerability profile of icatibant. }\end{array}$ \\
\hline
\end{tabular}

${ }^{a}$ At the time of this study, icatibant was licensed for administration by healthcare providers only; it is now licensed for self-administration. $\mathrm{C} 1-\mathrm{INH}=\mathrm{C} 1$ esterase inhibitor; $\mathrm{HAE}=$ hereditary angioedema.

or received home healthcare assistance (3.5\%) [48]. Furthermore, a recent survey (conducted between November 2010 and February 2011) showed that many international physicians neither adhere to the 2010 International Consensus Algorithm for treating HAE nor follow current evidence-based studies [49]; however, until recently, some physicians have been unable to adhere to such guidelines because of lack of approval of HAE treatments in their countries [48]. Since the US survey, clinical experience has increased significantly and this should help to improve compliance with current treatment recommendations. For example, in Frankfurt University Hospital, where C1-INH therapy has been available for many years, $74 \%$ of patients with HAE receive on-demand C1-INH therapy, $49 \%$ of patients are self-administering their therapy and treatment is individualised to limit disruption to normal daily activities [18].

These inconsistent treatment approaches are a concern and warrant investigation into potential barriers that prevent adherence with current recommendations. Emphasis should be placed on the education of physicians and nurses to raise their awareness of, and compliance with current HAE treatment recommendations. Patients should also be encouraged to take a proactive role in the management of their condition.

\section{Conclusion}

In summary, consensus group meetings have recommended that self-administration and self-possession of treatment are beneficial to patients with HAE. Recent studies have confirmed this showing that acute attacks are resolved quickly and safely with self-treatment, minimising the burden of disease. To date, guidelines essentially see only pasteurised-nanofiltered C1-INH and icatibant as real self-administration opportunities; however, ecallantide is approved for home-administration by a healthcare provider in the USA. Resources need to be maximised to encourage more patients to move to self-administration and to increase physicians' awareness of treatment recommendations.

\section{Disclosure Statement}

Professor Cicardi has a consultancy agreement with Sigma Tau and has been involved in advisory boards for CSL Behring, Dyax, ViroPharma and Sobi.

Dr. Craig speaks for CSL Behring, ViroPharma, Shire and Dyax. He does research for Pharming, CSL Behring, ViroPharma, Shire and Dyax. He is a consultant for CSL Behring and Dyax and has received educational grants from Dyax, ViroPharma and CSL Behring. 
Dr. Martinez-Saguer gives lectures or is a consultant for the following companies: Bayer, Baxter, CSL Behring, Jerini/shire, Octapharma and Sobi.

Dr. Hébert is a consultant for GSK, Novartis, Merck, Paladin, Pfizer and Hollister Stier, and does clinical research for Circassia, BI, GSK, Merck, Novartis, AstraZeneca, Shire, Janssen and Pfizer.

Dr. Longhurst and members of her department have received funding to attend conferences and other educational events, have acted as medical advisors or speakers, have received donations to her departmental fund, have received financial and other assistance with patient care projects and/or have participated in clinical trials with the following companies: CSL Behring, Pharming/ Swedish Orphan Biovitrum, Jerini/Shire, Dyax, ViroPharma, Baxter and Grifols.

\section{References}

$\checkmark 1$ Bowen T, Hebert J, Ritchie B, Burnham J, MacSween M, Warrington R, Yang W, Issekutz A, Karitsiotis N, McCombie N, Giulivi T: Management of hereditary angioedema: a Canadian approach. Transfus Apher Sci 2003; 29:205-214.

-2 Bowen T, Cicardi M, Farkas H, Bork K, Kreuz W, Zingale L, Varga L, Martinez-Saguer I, Aygören-Pürsün E, Binkley K, Zuraw B, Davis A 3rd, Hebert J, Ritchie B, Burnham J, Castaldo A, Menendez A, Nagy I, Harmat G, Bucher C, Lacuesta G, Issekutz A, Warrington R, Yang W, Dean J, Kanani A, Stark D, McCusker C, Wagner E, Rivard GE, Leith E, Tsai E, MacSween M, Lyanga J, Serushago B, Leznoff A, Waserman S, de Serres J: Canadian 2003 International Consensus Algorithm for the Diagnosis, Therapy, and Management of Hereditary Angioedema. J Allergy Clin Immunol 2004;114:629-637.

- 3 Craig T, Aygören-Pürsün E, Bork K, Bowen T, Boysen H, Farkas H, Grumach A, Katelaris $\mathrm{CH}$, Lockey R, Longhurst $\mathrm{H}$, Lumry W, Magerl M, Martinez-Saguer I, Ritchie B, Nast A, Pawankar R, Zuraw B, Maurer M: WAO Guideline for the Management of Hereditary Angioedema. World Allergy Organ J 2012;5: 182-199.

4 Bork K: Current management options for hereditary angioedema. Curr Allergy Asthma Rep 2012;12:273-280.

5 Gompels MM, Lock RJ, Abinun M, Bethune CA, Davies G, Grattan C, Fay AC, Longhurst HJ, Morrison L, Price A, Price M, Watters D: $\mathrm{C} 1$ inhibitor deficiency: consensus document. Clin Exp Immunol 2005;139:379-394.

-6 Agostoni A, Aygören-Pürsün E, Binkley KE, Blanch A, Bork K, Bouillet L, Bucher C, Castaldo AJ, Cicardi M, Davis AE, De Carolis C, Drouet C, Duponchel C, Farkas H, Fáy K, Fekete B, Fischer B, Fontana L, Füst G, Giacomelli R, Gröner A, Hack CE, Harmat G, Jakenfelds J, Juers M, Kalmár L, Kaposi PN, Karádi I, Kitzinger A, Kollár T, Kreuz W, Lakatos P, Longhurst HJ, Lopez-Trascasa M, Martinez-Saguer I, Monnier N, Nagy I, Németh E, Nielsen EW, Nuijens JH, O'Grady C, Pappalardo E, Penna V, Perricone C, Perricone R, Rauch U, Roche O, Rusicke E, Späth PJ, Szendei G, Takács E, Tordai A, Truedsson L, Varga L, Visy B, Williams K, Zanichelli A, Zingale L: Hereditary and acquired angioede- ma: problems and progress: proceedings of the third $\mathrm{Cl}$ esterase inhibitor deficiency workshop and beyond. J Allergy Clin Immunol 2004;114:S51-S131.

7 Bork K, Hardt J, Schicketanz KH, Ressel N: Clinical studies of sudden upper airway obstruction in patients with hereditary angioedema due to $\mathrm{C} 1$ esterase inhibitor deficiency. Arch Intern Med 2003;163:1229-1235.

-8 Cicardi M, Bergamaschini L, Marasini B, Boccassini G, Tucci A, Agostoni A: Hereditary angioedema: an appraisal of 104 cases. Am J Med Sci 1982;284:2-9.

-9 Longhurst HJ, Carr S, Khair K: C1-inhibitor concentrate home therapy for hereditary angioedema: a viable, effective treatment option. Clin Exp Immunol 2007;147:11-17.

10 Bork K, Meng G, Staubach P, Hardt J: Treatment with $\mathrm{C} 1$ inhibitor concentrate in abdominal pain attacks of patients with hereditary angioedema. Transfusion 2005;45:17741784.

11 Bork K, Witzke G: Long-term prophylaxis with $\mathrm{C} 1$-inhibitor (C1 INH) concentrate in patients with recurrent angioedema caused by hereditary and acquired C1-inhibitor deficiency. J Allergy Clin Immunol 1989;83:677682.

12 Kreuz W, Fischer D, Martinez-Saguer I, Heller C, Klarmann D: C1-esterase inhibitor substitution in hereditary angioedema. Biomed Prog 1999;12:1-7.

13 Kreuz W, Martinez-Saguer I, AygörenPürsün E, Rusicke E, Klingebiel T: Individual replacement therapy (IRT) with a pasteurized C1-inhibitor concentrate compared to prophylaxis with danazol in patients with hereditary angioedema (HAE) - a prospective study. Blood 2004;104:1028 (abstract).

14 Levi M, Choi G, Picavet C, Hack CE: Self-administration of C1-inhibitor concentrate in patients with hereditary or acquired angioedema caused by C1-inhibitor deficiency. J Allergy Clin Immunol 2006;117:904-908.

15 Rusicke E, Martinez-Saguer I, AygörenPürsün E, Kreuz W: Home treatment in patients with hereditary angioedema (HAE). J Allergy Clin Immunol 2006;117:S180.

-16 Strawczynski H, Stachewitsch A, Morgenstern G, Shaw ME: Delivery of care to hemophiliac children: home care versus hospitalization. Pediatrics 1973;51:986-991.
17 Bowen T, Cicardi M, Bork K, Zuraw B, Frank M, Ritchie B, Farkas H, Varga L, Zingale LC, Binkley K, Wagner E, Adomaitis P, Brosz K, Burnham J, Warrington R, Kalicinsky C, Mace S, McCusker C, Schellenberg R, Celeste L, Hebert J, Valentine K, Poon MC, Serushago B, Neurath D, Yang W, Lacuesta G, Issekutz A, Hamed A, Kamra P, Dean J, Kanani A, Stark D, Rivard GE, Leith E, Tsai E, Waserman S, Keith PK, Page D, Marchesin S, Longhurst HJ, Kreuz W, Rusicke E, Martinez-Saguer I, Aygören-Pürsün E, Harmat G, Füst G, Li H, Bouillet L, Caballero T, Moldovan D, Späth PJ, Smith-Foltz S, Nagy I, Nielsen EW, Bucher C, Nordenfelt P, Xiang ZY: Hereditary angiodema: a current state-of-the-art review, VII: Canadian Hungarian 2007 International Consensus Algorithm for the Diagnosis, Therapy, and Management of Hereditary Angioedema. Ann Allergy Asthma Immunol 2008;100:S30-S40.

18 Aygören-Pürsün E, Martinez-Saguer I, Rusicke E, Klingebiel T, Kreuz W: On demand treatment and home therapy of hereditary angioedema in Germany - the Frankfurt experience. Allergy Asthma Clin Immunol 2010;6:21.

19 CSL Behring: CSL Behring announces completion of national marketing authorizations of Berinert ${ }^{\circledR}$ after MRP in 23 European countries. 2011. http://www.cslbehring.com/PRelease/Berinert-Approved.htm?tabSelections= $1255923338674 \&$ currentPage $=1($ accessed 21 November 2012).

20 Food and Drug Administration: FDA approves Berinert to treat abdominal attacks, facial swelling associated with hereditary angioedema. 2009. http://www.fda.gov/NewsEvents/Newsroom/Press Announcements/2009/ ucm 186257.htm (accessed 21 November 2012).

21 Food and Drug Adminstration: Cinryze approval. 2008. http://www.fda.gov/BiologicsBloodVaccines/BloodBloodProducts/ApprovedProducts/LicensedProductsBLAs/ FractionatedPlasmaProducts/ucm 150480 . htm (accessed 21 November 2012).

22 ViroPharma Inc.: ViroPharma receives complete response letter for Cinryze ${ }^{\mathrm{TM}}$ supplemental biologics licence application for acute treatment of hereditary angioedema. 2009. http://ir.viropharma.com/releasedetail. cfm?ReleaseID=543136 (accessed 21 November 2012). 
23 Waknine Y: FDA approves ecallantide for hereditary angioedema. 2009. http://www. medscape.com/viewarticle/713401 (accessed 21 November 2012).

24 Shire: Jerini receives European Commission approval for Firazyr (icatibant) in the treatment of HAE. 2008. http://www.shire.com/ shireplc/en/media/shirenews?year=2008 (accessed 21 November 2012).

25 Longhurst HJ, Farkas H, Craig T, AygörenPürsün E, Bethune C, Bjorkander J, Bork K, Bouillet L, Boysen H, Bygum A, Caballero T, Cicardi M, Dempster J, Gompels M, Gooi J, Grigoriadou S, Huffer U, Kreuz W, Levi MM, Long J, Martinez-Saguer I, Raguet M, Reshef A, Bowen T, Zuraw B: HAE international home therapy consensus document. Allergy Asthma Clin Immunol 2010;6:22.

- 26 Bowen T, Cicardi M, Farkas H, Bork K, Longhurst HJ, Zuraw B, Aygoeren-Pürsün E, Craig T, Binkley K, Hebert J, Ritchie B, Bouillet L, Betschel S, Cogar D, Dean J, Devaraj R, Hamed A, Kamra P, Keith PK, Lacuesta G, Leith E, Lyons H, Mace S, Mako B, Neurath D, Poon MC, Rivard GE, Schellenberg R, Rowan D, Rowe A, Stark D, Sur S, Tsai E, Warrington R, Waserman S, Ameratunga R, Bernstein J, Björkander J, Brosz K, Brosz J, Bygum A, Caballero T, Frank M, Fust G, Harmat G, Kanani A, Kreuz W, Levi M, Li H, Martinez-Saguer I, Moldovan D, Nagy I, Nielsen EW, Nordenfelt P, Reshef A, Rusicke E, Smith-Foltz S, Späth P, Varga L, Xiang ZY: 2010 International consensus algorithm for the diagnosis, therapy and management of hereditary angioedema. Allergy Asthma Clin Immunol 2010;6:24.

27 Zuraw BL, Busse PJ, White M, Jacobs J, Lumry W, Baker J, Craig T, Grant JA, Hurewitz D, Bielory L, Cartwright WE, Koleilat M, Ryan W, Schaefer O, Manning M, Patel P, Bernstein JA, Friedman RA, Wilkinson R, Tanner D, Kohler G, Gunther G, Levy R, McClellan J, Redhead J, Guss D, Heyman E, Blumenstein BA, Kalfus I, Frank MM: Nanofiltered C1 inhibitor concentrate for treatment of hereditary angioedema. N Engl J Med 2010;363: 513-522.

28 Zuraw B, Cicardi M, Levy RJ, Nuijens JH, Relan A, Visscher S, Haase G, Kaufman L, Hack CE: Recombinant human C1-inhibitor for the treatment of acute angioedema attacks in patients with hereditary angioedema. J Allergy Clin Immunol 2010;126:821-827.

-29 Cicardi M, Banerji A, Bracho F, Malbrán A, Rosenkranz B, Riedl M, Bork K, Lumry W, Aberer W, Bier H, Bas M, Greve J, Hoffmann TK, Farkas H, Reshef A, Ritchie B, Yang W, Grabbe J, Kivity S, Kreuz W, Levy RJ, Luger T, Obtulowicz K, Schmid-Grendelmeier P, Bull C, Sitkauskiene B, Smith WB, Toubi E, Werner S, Anné S, Björkander J, Bouillet L, Cillari E, Hurewitz D, Jacobson KW, Katelaris CH,
Maurer M, Merk H, Bernstein JA, Feighery C, Floccard B, Gleich G, Hébert J, Kaatz M, Keith $\mathrm{P}$, Kirkpatrick $\mathrm{CH}$, Langton $\mathrm{D}$, Martin L, Pichler C, Resnick D, Wombolt D, Fernández Romero DS, Zanichelli A, Arcoleo F, Knolle J, Kravec I, Dong L, Zimmermann J, Rosen K, Fan WT: Icatibant, a new bradykinin-receptor antagonist, in hereditary angioedema. $\mathrm{N}$ Engl J Med 2010;363:532-541.

30 Cicardi M, Levy RJ, McNeil DL, Li HH, Sheffer AL, Campion M, Horn PT, Pullman WE: Ecallantide for the treatment of acute attacks in hereditary angioedema. N Engl J Med 2010; 363:523-531.

- 31 Levy RJ, Lumry WR, McNeil DL, Li HH, Campion M, Horn PT, Pullman WE: EDEMA4: a phase 3, double-blind study of subcutaneous ecallantide treatment for acute attacks of hereditary angioedema. Ann Allergy Asthma Immunol 2010;104:523-529.

32 Craig TJ, Levy RJ, Wasserman RL, Bewtra AK, Hurewitz D, Obtulowicz K, Reshef A, Ritchie B, Moldovan D, Shirov T, Grivcheva-Panovska V, Kiessling PC, Keinecke HO, Bernstein JA: Efficacy of human C1 esterase inhibitor concentrate compared with placebo in acute hereditary angioedema attacks. J Allergy Clin Immunol 2009;124:801-808.

33 Bowen T: Hereditary angioedema: beyond international consensus - circa December 2010 - The Canadian Society of Allergy and Clinical Immunology Dr. David McCourtie Lecture. Allergy Asthma Clin Immunol 2011;7:1.

34 ViroPharma Inc.: ViroPharma's Cinryze ${ }^{\circledR}$ (C1 inhibitor [human]) granted European marketing authorization for hereditary angioedema (HAE). 2011. http://ir.viropharma. $\mathrm{com} /$ releasedetail.cfm? ReleaseID $=585060$ (accessed 21 November 2012).

35 Shire: FDA approves Shire's Firazyr (icatibant injection) for acute attacks of hereditary angioedema (HAE). 2011. http://www.shire. com $/$ shireplc/en $/$ media/shirenews?id $=520$ (accessed 21 November 2012).

36 European Commission approves self-administration label for Firazyr ${ }^{\circledR}$ (icatibant) for the symptomatic treatment of acute hereditary angioedema attacks. 2011. http://www. pharmiweb.com/PressReleases/pressrel. asp?ROW_ID=37878\#axzz2Cm0UVl3D (accessed 21 November 2012).

37 CSL Behring: CSL Behring receives European Health Authorities' approval for self-administration of Berinert ${ }^{\circledR}$. 2011. http://www.cslbehring.com/news-room/european-healthauthorities-approve-self-adminstration-ofberinert.htm (accessed 21 November 2012).

38 CSL Behring: CSL Behring receives FDA approval of expanded label on Berinert ${ }^{\circledR}$ for selfadministration and treatment of acute laryngeal attacks of hereditary angioedema. 2012. http://www.cslbehring-us.com/news-room/ HAE-Berinert-Self-Administration-and-La-
ryngeal-Attacks (accessed 21 November 2012).

39 CSL Behring: CSL Behring receives European Health Authorities' approval of Berinert ${ }^{\mathbb{B}}$ for short-term prophylaxis in adults and children. 2013. http://www.cslbehring.com/s1/cs/enco/ $1151517263302 /$ news/1255931201677/ prdetail.htm (accessed 17 April 2013).

40 Cicardi M, Bork K, Caballero T, Craig T, Li $\mathrm{HH}$, Longhurst $\mathrm{H}$, Reshef A, Zuraw B, HAWK: Evidence-based recommendations for the therapeutic management of angioedema owing to hereditary $\mathrm{C} 1$ inhibitor deficiency: consensus report of an International Working Group. Allergy 2012;67:147-157.

41 Kreuz W, Martinez-Saguer I, AygörenPürsün E, Rusicke E, Heller C, Klingebiel T: $\mathrm{C} 1$-inhibitor concentrate for individual replacement therapy in patients with severe hereditary angioedema refractory to danazol prophylaxis. Transfusion 2009;49:1987-1995.

42 Wahn V, Aberer W, Eberl W, Fasshauer M, Kühne T, Kurnik K, Magerl M, Meyer-Olson D, Martinez-Saguer I, Späth P, StaubachRenz P, Kreuz W: Hereditary angioedema (HAE) in children and adolescents-a consensus on therapeutic strategies. Eur J Pediatr 2012;171:1339-1348.

43 Tourangeau LM, Castaldo AJ, Davis DK, Koziol J, Christiansen SC, Zuraw BL: Safety and efficacy of physician-supervised selfmanaged $\mathrm{C} 1$ inhibitor replacement therapy. Int Arch Allergy Immunol 2012;157:417424.

44 Kreuz W, Rusicke E, Martinez-Saguer I, Aygören-Pürsün $\mathrm{E}$, Heller $\mathrm{C}$, Klingebiel $\mathrm{T}$ : Home therapy with intravenous human C1inhibitor in children and adolescents with hereditary angioedema. Transfusion 2012;52: 100-107.

45 Bygum A, Andersen KE, Mikkelsen CS: Selfadministration of intravenous $\mathrm{C} 1$-inhibitor therapy for hereditary angioedema and associated quality of life benefits. Eur J Dermatol 2009;19:147-151.

46 Farkas H, Csuka D, Zotter Z, Varga L, Böröcz Z, Temesszentandrási G, Jakab L, Karádi I: Home treatment of hereditary angioedema with icatibant administered by health care professionals. J Allergy Clin Immunol 2012; 129:851-852.

47 Boccon-Gibod I, Bouillet L: Safety and efficacy of icatibant self-administration for acute hereditary angioedema. Clin Exp Immunol 2012;168:303-307.

48 Riedl M: Hereditary angioedema therapies in the United States: movement toward an international treatment consensus. Clin Ther 2012;34:623-630.

49 Dispenza MC, Craig TJ: Discrepancies between guidelines and international practice in treatment of hereditary angioedema. Allergy Asthma Proc 2012;33:241-248. 